\title{
Credit Risk Determinants of Bank Failure: Evidence from US Bank Failure
}

\author{
Abdus Samad \\ Correspondence: Abdus Samad, Associate Professor, Department of Finance and Economics, Utah Valley \\ University, 800 W University PKY, Orem, UT 84058, USA. Tel: 1-801-863-8368. E-mail: \\ abdus.samad@uvu.edu
}

Received: June 14, 2012

Accepted: July 13, $2012 \quad$ Online Published: July 31, 2012

doi:10.5539/ibr.v5n9p10

URL: http://dx.doi.org/10.5539/ibr.v5n9p10

\begin{abstract}
This paper empirically determines the significant determinants, among credit risk variables, of US bank failure. Applying the Probit Model the paper finds that among the five credit risk variables, the credit loss provision to net charge off, loan loss allowance to non-current loans, and non-current loans to loans are significant for predicting bank failures. These factors predict 76.8 percent to 77.25 of total observation correctly. The model predicts 97 out of 121 failures i.e. 80.17 percent correctly. Net charge off to loans and loan loss to non-current loans, though most reliable measures, are not significant predictors for the US bank failures during 2009.
\end{abstract}

JEL Classification: F21, G20, G21

Keywords: bank failure, credit risk, probit, net-charge off, non-current loans

\section{Introduction}

There were 25 bank failures in 2008 (Samad \& Lowell, 2012). 140 banks went burst in 2009 and 157 banks were wipped out in 2010 (Time, January 2012). Such a large scale bank failure hasnot happened in the financial history of the United States since the Great Depression. It has resulted in global financial crisis in Europe and around world.

There are several theories that have led to bank failures. One of them is the insolvency theory. According to the insolvency theory, a bank fails when the value of bank assets fall and becomes less than its liabilities. In most cases the value of assets fall due to credit risk resulting from nonperformance of loans. Credit risks are measured by credit risk ratios.

Since a majority of a bank's assets are in the form of loans, credit risk is a major risk for a bank. Credit risk is mainly a function of the quality of a bank's loans. It is an internal factor, amenable to bank management. Credit risk is measured by several ratios. They include (i) net charge off to loans, (ii) credit loss provision to net charge off (iii) loss allowance to loans (iv) loan loss allowance to non-current loans, and (v) non-current loans to loans. According to Pantalone and Marjorie (1987), bank internal factors continue to be the significant factor contributing to at least one-third of the bank failures. However, which of a bank's internal factors in credit risk measures are significant in predicting bank failures that have not been explored quantitatively and deserves examination and exploration.

The objective of this paper is to identify the credit risk ratios that are significant in predicting the US bank failures during 2009. Identifying the risk ratios that are significant predictors of bank failures are of great importance to bank customers, bank examiners and bank management. Identifying the significant risk ratios can reduce the length of time losses and the misallocation of resources (Meyer \& Pifer, 1970).

The identification of significant credit risk factor i.e. credit risk ratio among various credit risk indicators is an important contribution of this paper in the banking literature.

The paper is organized as: a brief survey of literature on bank failureas outlined in Section 2. Data and methodology is discussed in Section 3. Empirical results and conclusions are provided in Section 4.

\section{Survey of Literature}

The literature on bank failure/closing is wide and as such it is inappropriate to provide a complete review of that material in this paper. Instead, this paper will limit the review to those studies that directly relate to the more specific criteria and processes that are evaluated in this analysis. 
Samad (2011) examined failed and non-failed banks using ANOVA and KrosKalWali tests and found failed banks had significantly lower capital ratio than those of non-failed banks.

Samad and Glenn (2012) examined the factors of US bank failure and found that T1RBCATA (Tier 1 risk based capital to total assets) TRBCRWA (total risk based capital to risk weighted assets), ROA (return on assets), ASTEMPM (total asset as percentage of full-time employee) and EFFICR (noninterest expense) significant factors in predicting bank failures during 2009. The five factors described above were found to correctly predict 86.4 percent of total bank failures.

Estrella, Park, and Perustuani (2000) examined the effectiveness of three capital ratios as a means for analyzing bank failures. Using the 1988-1993 data for US banks, they observed that the simple leverage ratio and gross revenue ratio, were the best two of the three ratios for predicting failure over a single year or two-year horizon.

Thomson (1991) studied the factors that influenced commercial bank failures during the 1980s. He also found that the economic environment in which banks operated affected the probability of bank failure. In his working paper (1989), Thomson models the regulatory decision to close a bank as a call option anda two equation model of bank failure was constructed from the call option. The model was estimated for the bank failure that occurred during 1984-1989.

Meyer and Pifer (1970) examined the causes of bank failure and concluded that failure resulted from such factors as embezzlement and other financial irregularities, as contrasted to normal, financial, concepts that are generally used to measures the relative strength of banks. Their study had methodological problems.

Martin's (1977) paper sought to construct an early warning model for bank failure as a function of several variables classified into four categories: asset risk, liquidity risk, capital adequacy, and earning and asset risk. Using the logit model on historical data for US banks he found that the two most significant factors in predicting failures were gross capital to risk assets, (significant at a 0.99 level) and commercial loans to total loans also at the 0.99 level of significance.

Pantalone and Platt (1987) also analyzed issues causing bank failure during the period following deregulation in the 1980's. In their model, they used management efficiency profitability, leverage, risk diversification, and the economic condition of the state. They found that the principal cause of bank failure was basically the same during the post deregulation period as it was prior to deregulation.

Sinkey $(1975,1975)$ applied univariate and bivariate (risk-return analysis) statistical procedures to the United States National Bank of San Diego's (USNB) balance-sheet and income statement characteristics prior to its collapse. His empirical results found statistically significant differences between the two groups of problem banks.

West (1985) used factor analysis and logit regression and Madala (1986) suggested a two step logit regression.

This survey of short literature (exclusive of Thomson (1991) and Meyer and Pifer (1970), demonstrates that the current study is different from previous studies in several ways. First there is the use of the ProbitModel. Previous studies did not use a probit model in bank failure. Second, there is no study dealing with identifying credit risk variables for the 2009 US bank failure as significant factors in predicting bank failures. There are two additional perspectives which this analysis contributes to the historical bank failure literature. This analysis directly identifies failed banks whereas almost all the previous studies used banks that were classified as problems banks. In addition, this paper uses a cross sectional analysis with a large number of bank failures whereas all previous studies dealt with a small number of banks classified as problem banks.

\section{Data and Methodology}

\subsection{Data}

As most of the US banks failed in 2009, this study uses 2009 data. Quarterly data for various credit risk ratios, in particular data for three quarters prior to bank failures, are obtained from the call reports of FDIC and Web site: WWW.FDIC.GOV.

A total of 255 banks-134 failed and 121non-failed banks-are considered. Non-failed banks are randomly chosen. In order to avoid the biasness of economic impact of states on failed banks, a similar number of non-failed banks is taken from the same state.

\subsection{Methodology}

Since dependent variable - failure $=1$ and success $=0$ - is binary, the Probit Model is used for identifying the credit risk ratios that are significant and have predictive power. 
Probit Model:

$$
\operatorname{Pr}\left(Y_{i}=1 \mid X_{i}, \beta\right)=1-\Phi\left(-X_{i}{ }^{\prime}-\beta\right)=\Phi\left(X_{i}{ }_{i} \beta\right)
$$

Where $\Phi$ is the cumulative density function of the standard normal distribution which takes a real value ranging between zero and one.

The probability functions used in the Probit Model are the standard normal distribution. Being distribution functions, they are symmetric around 0 and variance equal 1 , and they are bounded between 0 and 1 (Amemiya, 1981).

Using the conventions of notation, the estimated model can be written in general form:

$$
\operatorname{Pr}\left(Y_{i}=1\right)=F\left(x_{i} 1, x_{i} 2, \ldots \ldots x_{i} M, \beta 1, \beta 2, \ldots \ldots\right)
$$

Where $Y_{\mathrm{i}}$ is a dependable variable which represents the final outcome: $Y_{\mathrm{i}}=1$ for failed banks, $\mathrm{Y}_{\mathrm{i}}=0$ for success banks. $X_{i}$ are the number of explanatory variables that have impact on bank failures or successes; $X_{i j}$ the value of ith variable for the ith observation. $\beta 1, \beta 2 \ldots \ldots$ coefficient associated with explanatory variable $X_{i}$ is estimated from the sample. In compact notation, (2) can be stated as:

$$
\operatorname{Pr}\left(Y_{i}=1\right)=\left(X_{i} \beta+U_{t}\right)
$$

Where $\mathrm{Y}=1, \mathrm{Y}=2, \mathrm{Y}=3$ are dependent variable representing failure or success $\left(\mathrm{Y}_{\mathrm{i}}=1\right.$ for failed banks, $\mathrm{Y}_{\mathrm{i}}=0$ for success banks) $X_{i t}$ is a (1x k) vector of explanatory variables used and $\beta$ is a $(\mathrm{k} \times 1)$ vector of unknown parameters to be estimated. $U_{t}$ is the white noise. Then the observed dependent variable $Y_{i}{ }^{*}$, is determined by whether y exceeds a threshold value, 0.5 , in this paper. That is,

$$
Y i=\begin{aligned}
& 1 \text { if } Y * \geq 0.5 \\
& 0 \text { if } Y *<0.5
\end{aligned}
$$

Robustness i.e. expectation-prediction of the model as well as the likelihood ratio (LR) statistics will be examined. The LR statistics tests the joint null-hypothesis that all slope coefficients are simultaneously equal to zero and is computed as $-2(1(\beta) / 1(\beta)$.

Marginal effects of probit variables are estimated. In probit or logit models, as $\mathrm{Y}$ is the density function of $\alpha_{0}$ $+\alpha_{1} X_{1}+\alpha_{2} X_{2}+\alpha_{3} X_{3}$, i.e.

$$
\begin{gathered}
Y=F\left(\alpha_{0}+\alpha_{1} X_{1}+\alpha_{2} X_{2}+\alpha_{3} X_{3}\right) \text {. The marginal effect of } X_{\mathrm{i}} \text { is calculated as: } \\
\frac{d y}{d X i}=F\left(\alpha_{0}+\alpha_{1} X_{1}+\alpha_{2} X_{2}+\ldots \ldots . \alpha_{n} X_{n}\right)^{*} \alpha_{i} .
\end{gathered}
$$

The model's goodness of fit is estimated from the Hosmer-Lameshow and Andrews tests.

\subsection{Dependent Variable}

$\mathrm{Y}_{\mathrm{i}}$ is binary variable: $\mathrm{Y}=1$ for failed banks; $\mathrm{Y}=0$ for survived banks

\subsection{Independent Variables}

Five credit risk ratios that US bank examiners periodically apply for determining bank risk are used as independent variables. They are:

(i) Net charge off to loans (X11)

(ii) Credit loss provision to net charge off (X12)

(iii) Loss allowance to loans (X17)

(iv) Loan loss allowance to non-current loans ( X18)

(v) Non-current loans to loans (X20).

Three alternative ProbitModels are estimated as:

$$
\begin{gathered}
Y=F(X 11, X 12, X 17, X 18, X 20) \\
Y=F(X 11, X 12, X 17, X 20) \\
Y=F(X 12, X 17, X 20)
\end{gathered}
$$

Where it is expected that

$$
\frac{\partial y}{\partial X 11}>0, \quad \frac{\partial y}{\partial X 12}>0, \quad \frac{\partial y}{\partial X 17}>0, \quad \frac{\partial y}{\partial X 18}>0, \quad \frac{\partial y}{\partial X 20}>0,
$$

Correlations among the variables are tested before they are used for avoiding spurious relation. Result of correlation is provided in Table 1. 
Table 1. Correlation Matrix

\begin{tabular}{llllrl}
\hline & X11 & X12 & X17 & \multicolumn{1}{c}{ X18 } & \multicolumn{1}{c}{ X20 } \\
\hline X11 & 1.000000 & -0.047775 & 0.410939 & -0.049483 & 0.538086 \\
X12 & -0.047775 & 1.000000 & 0.035472 & 0.010963 & -0.051517 \\
X17 & 0.410939 & 0.035472 & 1.000000 & -0.045590 & 0.611945 \\
X18 & -0.049483 & 0.010963 & -0.045590 & 1.000000 & -0.076047 \\
X20 & 0.538086 & -0.051517 & 0.611945 & -0.076047 & 1.000000 \\
\hline
\end{tabular}

Table 1 shows no strong correlation among five variables. Since there is no strong correlation, they can be used together or in any order.

\section{Empirical Results and Conclusions}

Empirical results of Model 1, Model 2 and Model 3 are provided in Table 2, Table 3 and Table 4.

Table 2. Probit Regression Results of Three Models

\begin{tabular}{|c|c|c|c|c|c|c|c|c|}
\hline \multicolumn{3}{|l|}{ Model 1} & \multicolumn{3}{|l|}{ Model 2} & \multicolumn{3}{|l|}{ Model 3} \\
\hline Variables & Coefficient & Z-Stat & Variables & Coefficient & Z-Stat & Variables & Coefficient & Z-Stat \\
\hline $\mathrm{X} 11$ & 0.0103 & 0.22 & $\mathrm{X} 11$ & 0.0105 & 0.22 & & & \\
\hline $\mathrm{X} 12$ & 0.0001 & $2.28^{* *}$ & $\mathrm{X} 12$ & 0.0001 & $2.15^{* *}$ & $\mathrm{X} 12$ & 0.0001 & $2.14^{* *}$ \\
\hline $\mathrm{X} 17$ & 0.2621 & $2.54^{*}$ & $\mathrm{X} 17$ & 0.2321 & $2.34^{*}$ & $\mathrm{X} 17$ & 0.2370 & $2.44^{* *}$ \\
\hline X18 & -0.0021 & -1.02 & & & & & & \\
\hline $\mathrm{X} 20$ & 0.1554 & $4.17^{*}$ & $\mathrm{X} 20$ & 0.1895 & $6.13^{*}$ & $\mathrm{X} 20$ & 0.1911 & $6.34^{*}$ \\
\hline $\mathrm{C}$ & -1.397 & $-4.86^{*}$ & $\mathrm{C}$ & -.166 & $-7.41^{*}$ & $\mathrm{C}$ & -1.66 & $-7.41^{*}$ \\
\hline \multicolumn{3}{|c|}{ Log Likelihood $=-111.17$} & \multicolumn{3}{|c|}{ Log Likelihood $=-112.94$} & \multicolumn{3}{|c|}{ Log Likelihood $=-112.97$} \\
\hline \multicolumn{3}{|c|}{ Restri.log likelihood $=-172.63$} & \multicolumn{3}{|c|}{ Restri.log likelihood $=-176.42$} & \multicolumn{3}{|c|}{ Restri.log likelihood $=-176.42$} \\
\hline \multicolumn{3}{|c|}{ LR statistics $(5 \mathrm{df})=122.93$} & \multicolumn{3}{|c|}{ LR statistics $(5 \mathrm{df})=126.95$} & \multicolumn{3}{|c|}{ LR statistics $(5 \mathrm{df})=126.89$} \\
\hline \multicolumn{3}{|c|}{ Probability of (LR statistics $)=0.000$} & \multicolumn{3}{|c|}{ Probability of (LR statistics $)=0.000$} & \multicolumn{3}{|c|}{ Probability of $(\mathrm{LR}$ statistics $)=0.000$} \\
\hline \multicolumn{3}{|c|}{ McFadden $\mathrm{R}^{2}=0.35$} & \multicolumn{3}{|c|}{ McFadden $\mathrm{R}^{2}=0.35$} & \multicolumn{3}{|c|}{ McFadden $\mathrm{R}^{2}=0.44$} \\
\hline \multicolumn{3}{|c|}{ Convergence achieved } & \multicolumn{3}{|c|}{ Convergence achieved } & \multicolumn{3}{|c|}{ Convergence achieved } \\
\hline \multicolumn{3}{|c|}{ After 9 iteration } & \multicolumn{3}{|c|}{ After 5 iteration } & \multicolumn{3}{|c|}{ After 5 iteration } \\
\hline \multicolumn{3}{|c|}{ Covariance matrix computed } & \multicolumn{3}{|c|}{ Covariance matrix computed } & \multicolumn{3}{|c|}{ Covariance matrix computed } \\
\hline \multicolumn{3}{|c|}{ Using second derivatives } & \multicolumn{3}{|c|}{ Using second derivatives } & \multicolumn{3}{|c|}{ Using second derivatives } \\
\hline \multicolumn{3}{|c|}{ Observation with : } & \multicolumn{3}{|c|}{ Observation with : } & \multicolumn{3}{|c|}{ Observation with : } \\
\hline$Y=0$ & 116 & & $\mathrm{Y}=0$ & 121 & & $Y=0$ & 121 & \\
\hline$Y=1$ & 134 & & $\mathrm{Y}=1$ & 134 & & $Y=1$ & 134 & \\
\hline
\end{tabular}

Note: ${ }^{*} 1$ percent level of significance, ${ }^{* *} 5$ percent level of significance.

All three models, in Table 2, provide the same information in terms of satisfying the (i) sign of coefficient and (ii) the significance of the coefficient of variables, except variable X18. The coefficients of all variables, X12 (credit loss provision to net charge off), X17 (loss allowance to loans) and X20 (non-current loans to loans) are positive they are expected in the models and they are statistically significant. The sign for the coefficient of X18, in Model 1, is negative, contrary to the expectation of models. However, it is not significant. The sign for the coefficient X11 (net charge off to loans) is positive but not significant.

Based on McFadden $\mathrm{R}^{2}$ which provides the explanatory power of variables in models, Model 3 provides the highest explanatory power. Because Model 3, explains 44 percent of the variation of the dependent variable (failure or success) compared to 35 percent of Model 1 and Model 2.

All three models demonstrate that three credit risk factors-X12 (credit loss provision to net charge off), X17 (loss allowance to loans) and X20 (non-current loans to loans) - are significant variables for US bank failure during 2009.

The most popular conventional variables such as net charge off to loans (X11) and loan loss to non-current loans(X18) are not significant predictors for the US bank failures during 2009.

The probability of (LR stat) rejects the joint null hypothesis that all slope coefficients except constant are zero. The LR statistics is computed as $-2(1(\beta)-1(\beta))$.

The result of marginal effect on failure prediction is present in Table 3 . 
Table 3. Marginal Effects after Probit

\begin{tabular}{llllllll}
\hline \multicolumn{2}{l}{$\mathrm{y}=\operatorname{Pr}(\mathrm{Y})($ predict $)=.62835481$} & \multicolumn{5}{l}{} \\
\hline Variable & $\mathrm{dy} / \mathrm{dx}$ & Std. Err. & $\mathrm{z}$ & $\mathrm{P}>|\mathrm{z}|$ & {$[5 \%$ C.I. } & $\mathrm{X}$ \\
\hline $\mathrm{X} 12$ & .0000434 & .00002 & 2.14 & 0.032 & $3.6 \mathrm{e}-06$ & .000083 & 301.558 \\
$\mathrm{X} 17$ & .0896477 & .03651 & 2.46 & 0.014 & .018096 & .161199 & 2.42501 \\
$\mathrm{X} 20$ & .0722732 & .01075 & 6.73 & 0.000 & .051211 & .093335 & 7.22172 \\
\hline
\end{tabular}

Among the three determinants of bank failures, loss allowance to loans (X17) shows that it has the highest marginal impact on dependent variable $(\mathrm{Y}=1)$ its marginal impact $\mathrm{Y}$ is 8.9 percent. The impact of non-current loans to loans (X20) on the failures or success is 7.2 percent. Credit loss provision to net charge off (X12) has the least impact on $\mathrm{Y}$, dependent variable.

An important point to note is that the marginal of all three probit variables i.e. X12, X17 and X20 on Y, bank failures is statistically significant with significant level of $0.03,0.01$ and 0.00 respectively and they contribute 62.83 percent probability of bank failures.

The marginal effect of model's predictive power on failure is 0.628 i.e. 62.8 percent.

Table 4. Prediction Results of Three Models

\begin{tabular}{|c|c|c|c|c|c|c|c|c|c|}
\hline & \multicolumn{3}{|c|}{ Model 1} & \multicolumn{3}{|c|}{ Model 2} & \multicolumn{3}{|c|}{ Model 3} \\
\hline & \multicolumn{3}{|c|}{ Estimated Equation } & \multicolumn{3}{|c|}{ Estimated Equation } & \multicolumn{3}{|c|}{ Estimated Equation } \\
\hline & $\mathrm{Y}=0$ & $\mathrm{Y}=1$ & Total & $\mathrm{Y}=0$ & $\mathrm{Y}=1$ & Total & $\mathrm{Y}=0$ & $\mathrm{Y}=1$ & Total \\
\hline $\mathrm{P}(\mathrm{Y}=1)<.5$ & 88 & 30 & 118 & 96 & 34 & 130 & 97 & 34 & 131 \\
\hline $\mathrm{P}(\mathrm{Y}=1)>.5$ & 28 & 104 & 132 & 25 & 100 & 125 & 24 & 100 & 124 \\
\hline Total & 116 & 134 & 250 & 121 & 134 & 255 & 121 & 134 & 255 \\
\hline Correct & 88 & 104 & 192 & 96 & 100 & 196 & 97 & 100 & 197 \\
\hline$\%$ correct & 75.86 & 77.61 & 76.80 & 79.34 & 74.63 & 76.86 & 80.17 & 74.63 & 77.25 \\
\hline$\%$ incorrect & 24.14 & 22.39 & 23.20 & 20.66 & 25.37 & 23.14 & 19.83 & 25.37 & 22.75 \\
\hline Total Gain* & 75.86 & -22.39 & 23.20 & 79.34 & -25.37 & 24.31 & 80.17 & -25.37 & 24.71 \\
\hline Percent Gain* & 75.86 & NA & 50.00 & 79.34 & NA & 51.24 & 80.17 & NA & 52.07 \\
\hline
\end{tabular}

Model 3, in Table 4, providesthe highest prediction power. The variables of Model 3-credit loss provision to net charge off (X12), loan loss allowance to loans (X17), and non-current loans to loans (X20) correctly predicts 197 out of total 255, i.e. 77.25 percent, whereas Model 1 and Model 2 predict 76.8 percent and 76.86 percent respectively.

In bank survival prediction, $\mathrm{y}=0$, the prediction of Model 3, stands superior to that of both Model 1 and Model 2 . Model 3 correctly predicts 80.17 percent of the bank survivals (with mistakes $=19.83$ percent) compared to Model 1 and Model 2 prediction 75.86 percent and 79.34 percent respectively.

In predicting bank failure, Model 1 provides superior prediction capability. The variables of Model 1, correctly predicts 104 out of 134 i.e. 77.61 percent of failure compared to 74.34 percent and 74.6 percent of Model 2 and Model 3 respectively.

Goodness of fit tests for all three models is estimated and provided in Table 5.

Table 5. Andrews and Hosmer-Lemeshow Goodness of Fit Tests for Three Models

\begin{tabular}{lllll}
\hline Model & Statistics & & Prob $\chi^{2}$ & \\
\hline \multirow{2}{*}{ Model 1 } & H-L Statistics & 9.52 & $\operatorname{Prob} \chi^{2}(8)$ & $=0.30$ \\
& Andrews Statistics & 29.42 & $\operatorname{Prob} \chi^{2}(10$ & $=0.001$ \\
\multirow{2}{*}{ Model 2 } & H-L Statistics & 10.63 & $\operatorname{Prob} \chi^{2}(8)$ & $=0.22$ \\
& Andrews Statistics & 38.43 & $\operatorname{Prob} \chi^{2}(10$ & $=.000$ \\
\multirow{2}{*}{ Model 3 } & H-L Statistics & 15.45 & $\operatorname{Prob} \chi^{2}(8)$ & $=0.05$ \\
& Andrews Statistics & 44.12 & $\operatorname{Prob} \chi^{2}(10$ & $=.000$ \\
\hline
\end{tabular}

Table 5 shows that the variables of Model 3, credit loss provision to net charge off (X12), loan loss allowance loans (X17), and non-current loans to loans (X20) provides the best fit compared to variables in Model 1 and Model 2 in satisfying both Hosmer-Lameshow and Andrews tests. Both tests suggest that there is no significant 
difference between the fitted expected values and actual values by group. H-L Statistics (15.45) and Andrews Statistics (44.12) associated with their Prob. Chi-Sq provides support for it, whereas variables in Model 1 and Model 2 provide conflicting results.

\section{Conclusions}

Two hundred fifty-five banks-134 failed and 121survived banks-are examined for determining significant credit ratios in predicting bank failures via Probit Model. Five variables, net charge off to loans (X11), credit loss provision to net charge of (X12), loan loss allowance to loans (X17), loan loss allowance to non-current loans (X18), and non-current loans to loans (X20) are used in estimating three alternative probit models for determining their signs, significance, predictive power, and goodness of fit tests.

Three variables such as credit loss provision to net charge of (X12), loan loss allowance loans (X17), and non-current loans to loans (X20) are found to be significant determinants for bank failures. These three variables provide 77.25 percent correct prediction.

In bank survival prediction $(\mathrm{y}=0)$, these variables (X12, X17, and X20 in Model 3) correctly predicts 80.17 percent of the banks that survived (with only 19.83 percent error).

The most popular variables such as net charge off to loans (X11) and loan loss to non-current loans (X18) are not significant predictors for the US bank failures during 2009.

\section{References}

Amemiya, T. (1981). Qualitative Response Models: A Survey. Journal of Economic Literature, XIX, (December), 1483-1536.

Estrella, A., Park, S., \& Perustuani, S. (2000). Capital ratios as predictors of Bank Failure. Economic Policy Review, 6(2), 33-52.

Maddala, G. S. (1986). Econometric Issues in the empirical Analysis of Thrift Institutions. Working Paper, 56, Federal Home Loan Bank.

Martin, D. (1977). Early Warning of Bank Failure. Journal of Banking and Finance, 1, 249-276. http://dx.doi.org/10.1016/0378-4266(77)90022-X

Meyer, P. A., \& Pifer, H. W. (1970). Prediction of Bank Failures. The Journal of Finance, 25(4), 853-868. http://dx.doi.org/10.1111/j.1540-6261.1970.tb00558.x

Pantalone, C. C., \& Platt, M. B. (1987). Predicting Commercial Bank Failure Since Deregulation. New England Economic Review, July/August, 37-47.

Samad, A. (2011). Is Capital Inadequacy a Factor for Bank Failure. Journal of Accounting and Finance, 11(4), $105-110$

Samad, A., \& Glenn, L. (2012). Determinant of Bank Failure: Evidence from US Failed Banks. International Research Journal of Applied Finance, 3(4), 463-479.

Sinkey, J. F. (1975). Problem Banks; Identification and Characteristics. Journal of Bank Research, 5, 208-217.

Sinkey, J. F. (1975). The Failure of United States National Bank of San Diego. Journal of Bank Research, 6, $8-24$.

Thomson, J. (1989). An Analysis of bank failure: 1984 to 1989. Working Paper, 8916, Federal Reserve Bank of Cleveland, 1-55.

Thomson, J. (1991). Predicting Bank Failures in the 1980s. Economic Review, 27(1), 9-20.

West, R. C. (1985). A factor-Analytic Approach to Bank condition. Journal of Banking of Finance, 9, 253-266. http://dx.doi.org/10.1016/0378-4266(85)90021-4 